Tropical Journal of Pharmaceutical Research November 2014; 13 (11): 1815-1823

ISSN: $1596-5996$ (print); 1596-9827 (electronic)

(C) Pharmacotherapy Group, Faculty of Pharmacy, University of Benin, Benin City, 300001 Nigeria.

All rights reserved.

Available online at http://www.tjpr.org

Original Research Article

http://dx.doi.org/10.4314/tjpr.v13i11.7

\title{
Metabolites from Actinomyces Strain H6552 Extract Inhibit Transforming Growth Factor-Mediated Pulmonary Fibrosis
}

\author{
Rhun Yian Koh ${ }^{1,2}$, Chooi Ling Lim ${ }^{1,2}$, Coy Choke $\mathrm{Ho}^{3}$, Bruce David Uhal ${ }^{4}$, Maha \\ Abdullah $^{1}$, Sharmili Vidyadaran ${ }^{1}$ and Heng Fong Seow ${ }^{1 *}$ \\ ${ }^{1}$ Department of Pathology, Faculty of Medicine and Health Sciences, Universiti Putra Malaysia, 43400 UPM Serdang, Selangor, \\ ${ }^{2}$ Department of Human Biology, School of Medicine, International Medical University, No. 126, Jalan Jalil Perkasa 19, Bukit \\ Jalil, 57000 Kuala Lumpur, ${ }^{3}$ Biotechnology Programme, School of Science and Technology, University Malaysia Sabah, Locked \\ Bag 2073, 88999 Kota Kinabalu, Sabah, Malaysia, ${ }^{4}$ Department of Physiology and Biomedical Sciences, Michigan State \\ University, 2201 Biomedical Physical Sciences, East Lansing, MI 48837, USA
}

*For correspondence: Email: shf@upm.edu.my; Tel: 603-8947 2387; Fax: 603-8946 4232

Received: 25 February 2014

Revised accepted: 13 September 2014

\begin{abstract}
Purpose: To evaluate the effects of H6552 extract in inhibiting transforming growth factor (TGF)mediated pulmonary fibrosis in vitro and in vivo.

Methods: Maximum-nontoxic dose (MNTD) of Actinomyces H6552 extract was determined using 3(4,5-dimethylthiazol-2-yl)-2,5-diphhenyltetrazolium bromide (MTT) assay. Effect of the extract on IMR90 lung fibroblasts proliferation was determined by calculating the population doubling time (PDT). Collagen gel contraction assay was carried out to determine cell contractility while $\alpha$-smooth muscle actin (SMA) level in cells was evaluated by quantitative real-time polymerase chain reaction (PCR) and immunostaining methods. A bleomycin-induced ICR mouse model was used in the study to determine the effect of the extract in vivo. The animals received treatments in two regimes: early treatment in which treatment was given on Day 0 and delayed treatment with treatment on Days 5 and 10. The animals were sacrificed on Day 14 and the lungs removed for histopathological assessment.

Results: The MNTD of the $H 6552$ extract was $1625 \pm 459.62 \mu \mathrm{g} / \mathrm{ml}$. H6552 extract significantly reduced TGF- $\beta$-mediated cell proliferation, gel contraction and $\alpha$-SMA expression. PDT was increased up to $83.84 \%$ in the treated cells. Gel contraction was inhibited by the addition of $1000 \mu \mathrm{g} / \mathrm{ml}$ of $H 6552$ extract. Immunostaining results revealed negligible $\alpha$-SMA antibody staining after H6552 extract treatment at $500 \mu \mathrm{g} / \mathrm{ml}$. The extract also inhibited lung injury (54\% reduction in Ashcroft score) when early treatment was provided. Delayed treatment with the extract did not show any significant changes in the animals.

Conclusion: H6552 extract inhibited TGF- $\beta$-induced pulmonary fibrosis and elucidation of its bioactive metabolites may yield a potential agent to treat the disease.
\end{abstract}

Keywords: Actinomyces H6552, Transforming growth factor- $\beta$, Cell contractility, $\alpha$-Smooth muscle actin, Pulmonary fibrosis

Tropical Journal of Pharmaceutical Research is indexed by Science Citation Index (SciSearch), Scopus, International Pharmaceutical Abstract, Chemical Abstracts, Embase, Index Copernicus, EBSCO, African Index Medicus, JournalSeek, Journal Citation Reports/Science Edition, Directory of Open Access Journals (DOAJ), African Journal Online, Bioline International, Open-J-Gate and Pharmacy Abstracts

\section{INTRODUCTION}

Idiopathic pulmonary fibrosis (IPF) is a disease caused by the scarring process in lungs. A high mortality rate is observed amongst IPF patients.
At least 5 million persons are affected by IPF worldwide [1]. The incidence of IPF is approximately 10.7 men per 100,000 and 7.4 women per 100,000 whereas the prevalence is 20.2 men per 100,000 and 13.2 women per 
100,000 [2]. Data has shown that the incidence of the disease is on the rise [1].

Although the origin of the disease remains unknown, the cytokine transforming growth factor-beta (TGF- $\beta$ ) has been thought to play an important role in the pathogenesis of IPF. Therefore, the expression, activity and intracellular signaling of the cytokine must be held under tight regulation. It has been shown that interference of the TGF- $\beta$ pathway attenuated fibrosis of different origins [3]. Currently, there is lack of treatment regimens for IPF. Various studies have been carried out to discover a new cure for the disease.

Natural products have been utilized in the treatment of various diseases, including fibrosis, for centuries. Plant-derived compounds are the most commonly used agents in alternative medicine. However, a number of novel therapeutic compounds are found to be derived from microbial sources. For example, EM 703, which is a derivate of erythromycin produced from a strain of actinomyces, alleviated pulmonary fibrosis in mice [4]. In the present study, we investigated the anti-fibrotic effect of an extract from a novel actinomyces strain, namely $\mathrm{H} 6552$.

H6552 shared a $99.2 \%$ similarity with Streptomyces griseus and it was classified in the genera Streptomyces [5].The acetone extract of H6552 demonstrated an inhibition of TGF- $\beta$ signal transduction in a screening system. The screening system consisted of a B lymphocyte cell line (DGA-2) with a plasmid harboring IgA promoter linked to luciferase reporter gene that responded to TGF- $\beta 1$ and a transfected $\mathrm{NIH}-3 \mathrm{~T} 3$ cell line (NCL-5) which expresses a high level of luciferase but not responsive to TGF- $\beta$. Active TGF- $\beta 1$ acted as an inducer and NCL was used as the control cell line in the experiment. When H6552 extract was added to DGA-2 cells, luciferase activity reduced significantly [5]. On the basis that the extract was able to inhibit TGF$\beta$ signaling, we postulated its potential in inhibiting pulmonary fibrosis in vitro and in vivo.

\section{EXPERIMENTAL}

\section{Culture, fermentation and acetone extraction of secondary metabolites from $\mathrm{H} 6552$}

Actinomycetes strain $\mathrm{H} 6552$ is a microorganism isolated from a soil sample collected under Shorea foxworthyi in the dipterocarp arboretum of Forest Research Institute of Malaysia (FRIM).
The microbe was grown on oatmeal agar at 25 ${ }^{\circ} \mathrm{C}$. To extract secondary metabolites produced by the actinomycete, a single colony of $\mathrm{H} 6552$ was inoculated into $50 \mathrm{ml}$ of mannitol-peptone liquid medium in an Erlenmeyer flask. The flask was agitated at $220 \mathrm{rpm}$ for 5 days at $25{ }^{\circ} \mathrm{C}$. Equal volume of acetone was added into the flask at the end of fermentation. The mixture was left at $4{ }^{\circ} \mathrm{C}$ overnight and filtered with Whatman filter paper (Schleicher \& Schuell, UK). Acetone in the mixture was evaporated using a rotary vacuum evaporator (Eyela, Japan) at $42{ }^{\circ} \mathrm{C}$. The remaining liquid extract was then freeze-dried and kept at $4{ }^{\circ} \mathrm{C}$.

\section{Cell culture}

The IMR-90 cell line was purchased from American Type Culture Collection (ATCC). These human lung fibroblasts were cultured in Minimal Essential Medium (MEM) (Invitrogen Corporation, USA) supplemented with $10 \mathrm{mM}$ sodium pyruvate (Sigma, USA), $10 \%$ fetal bovine serum (FBS) (Gibco, Invitrogen Corporation, Denmark), penicillin (100 IU/ml), and streptomycin $(100 \mu \mathrm{g} / \mathrm{ml})$ (Gibco, Invitrogen Corporation, Denmark) at $37{ }^{\circ} \mathrm{C}$ in a humidified atmosphere of $95 \%$ air and $5 \%$ carbon dioxide $\left(\mathrm{CO}^{2}\right)$. IMR-90 cells between passages 12 and 20 were used in the experiments.

\section{Maximum non-toxic dose (MNTD) determination by MTT assay}

IMR-90 cells were seeded onto a 96-well plate at a density of 3000 cells per well. The cells were incubated with $\mathrm{H} 6552$ extract in a series of concentrations for $72 \mathrm{~h}$. Ten microliters of 5 $\mathrm{mg} / \mathrm{ml} \quad$ MTT (3-(4,5-dimethylthiazol-2-yl)-2,5diphhenyltetrazolium bromide) (Amresco, USA) was then added into each well and incubated for $4 \mathrm{~h}$ at $37{ }^{\circ} \mathrm{C}$ in a humidified atmosphere of $95 \%$ air and $5 \% \mathrm{CO}_{2}$. Solution in wells was replaced with $100 \mu \mathrm{l}$ dimethyl sulfoxide (DMSO) (Amresco, USA) and absorbance was read at $570 \mathrm{~nm}$. Untreated IMR-90 cells served as the control. Cell cytotoxicity was calculated as in Eq 1.

$$
\text { Cytotoxicity }(\%)=\{(\mathrm{Ca}-\mathrm{Ta}) / \mathrm{Ca}\} \times 100 \% \ldots . .(1)
$$

where $\mathrm{Ca}$ is the absorbance of control and $\mathrm{Ta}$ is the absorbance of treated cells

\section{Population doubling time (PDT) determination}

PDT was used to estimate the cell cycle time. Briefly, $1 \times 10^{4}$ IMR-90 cells were seeded into 24-well plates and treated with TGF- $\beta 1$ (10 $\mathrm{ng} / \mathrm{ml}$ ) (R\&D Systems, USA) alone or simultaneously with H6552 extract or SB 431542 
$(50 \mu \mathrm{M})$ (Sigma, USA) for $24 \mathrm{~h}$. The cell number was determined by Trypan blue (Sigma, USA) exclusion and a manual haemocytometer. PDT was calculated by dividing the total duration in hours by number of generations. The number of generations was calculated using Eq 2 .

No. of generations $=3.32(\log N N-\log N 1) \ldots . .(2)$

where $\mathrm{NN}$ represents the number of cells counted and $\mathrm{N} 1$ is the number of cells inoculated.

\section{Reverse transcription and real-time PCR}

IMR-90 cells were seeded onto a 6 -well plate at a density of $2 \times 10^{5}$ cells per well and allowed to attach overnight. The cells were treated with TGF- $\beta 1$ alone or simultaneously with $\mathrm{H} 6552$ extract or SB 431542 for $72 \mathrm{~h}$ after $24 \mathrm{~h}$ of serum starvation. Total RNA was then extracted using Tri-Reagent (Molecular Research Center Inc., USA) and reverse-transcribed into CDNA according to the manufacturer's protocol (Promega, USA).

cDNA samples were analyzed with Real-time PCR (Rotor-Gene RG300, Corbett Research, Australia) to determine changes in $\alpha$-smooth muscle actin ( $\alpha-S M A)$ expression. The primer sequences are: a-SMA (forward: 5'ACTGGGACGACATGGAAAAG-3', reverse: 5'AGATGGGGACATTGTGGGT-3'), GAPDH (forward: 5'-ACCACAGTCCATGCCATCAC-3', reverse: 5'-TCCACCACCCTGTTGCTGTA-3'). The amplification curves were analyzed with Rotor-Gene Analysis Software 6.0. Cycle threshold $\left(C_{t}\right)$ values of each target gene were normalized to GAPDH, and the fold change in mRNA expression compared to the control group was calculated.

\section{Immunocytochemical staining}

IMR-90 cells were seeded onto cover slips in a 24-well plate. The cells were then treated with TGF- $\beta$ alone or simultaneously with $\mathrm{H} 6552$ extract or SB 431542 for $48 \mathrm{~h}$ after $24 \mathrm{~h}$ of serum starvation.

The IMR-90 cells were then fixed with $100 \%$ methanol for $20 \mathrm{~min}$ at $4{ }^{\circ} \mathrm{C}$ and subsequently washed thrice (5 min each) with $0.1 \%$ Triton- $X$ in Tris-buffered saline (TBS). The cells were then incubated with hydrogen peroxide for $30 \mathrm{~min}$ followed by washing again with TBS. Blocking for $1 \mathrm{~h}$ with $3 \%$ bovine serum albumin in TBS was done and anti- $\alpha$-SMA antibody (1:300) (Sigma, USA) was added to the cells. After one-hour incubation with the primary antibody and washing thrice with $0.1 \%$ Triton- $X$ in TBS, the cells were incubated for $1 \mathrm{~h}$ with horseradish peroxidaseconjugated rabbit anti-mouse $\operatorname{lgG}$ at a dilution of 1:500 in blocking buffer. After three washes, DAB (3,3'- diaminobenzidine) substrate was added into each well and removed after brown color development and the coverslips were mounted on slides. The slides were then viewed under microscope and images were captured by camera. Total and positively stained cells numbers were then counted.

\section{Collagen gel contraction assay}

Collagen lattices were prepared in $30 \mathrm{~mm}$ sterile bacteriological petri dishes, to which fibroblasts adhere poorly. Each petri dish contained $250 \mu \mathrm{l}$ of $2 x$ MEM, $250 \mu \mathrm{l}$ of FBS, $62.5 \mu \mathrm{l}$ of $0.1 \mathrm{M}$ sodium hydroxide, $375 \mu \mathrm{l}$ of collagen solution and $250 \mu \mathrm{l}$ of IMR-90 cells suspended in MEM. Extracts were then added into the dishes, which were subsequently incubated at $37^{\circ} \mathrm{C}$ in a $5 \%$ $\mathrm{CO}_{2} / 95 \%$ air atmosphere. Gels incorporating the fibroblasts set completely after $10 \mathrm{~min}$.

To measure lattice diameters, the dishes were placed on a transparent metric ruler on a dark background. Contracted gels appeared as wellformed discs and the diameters of the discs were measured daily.

\section{Animal model and treatment protocol}

ICR female mice (Harlan Laboratories, USA) at 7 to 8 weeks of age were housed under special pathogen-free conditions in a satellite facility of University Laboratory Animal Resources, Michigan State University (MSU), USA. The use of animals in the study was approved by Institutional Animal Care and Use Committee, MSU and the protocols used were in accordance to guide for the care and use of laboratory animals [6]. The ICR mice were randomly divided into the following groups: normal saline alone (control), bleomycin $(1 \mathrm{U} / \mathrm{kg})$ alone, bleomycin and SB $431542(0.17 \mathrm{mg} / \mathrm{kg})$, SB 431542 alone, bleomycin and $\mathrm{H} 6552$ extract $(0.25 \mathrm{mg} / \mathrm{kg})$, and H6552 extract alone. Each group contained 6 animals.

The mice received treatment in two regimes: (1) Early treatment protocol: ICR mice received bleomycin simultaneously with treatment (SB 431542 or $\mathrm{H} 6552$ extract) on day 0 and sacrificed on day 14; (2) Delayed treatment protocol: ICR mice received bleomycin on day 0 , SB 431542 or H6552 extract given on day 5 and day 10 and the mice were sacrificed on day 14 . 
For bleomycin or treatment administration, mice were first anesthetized with sodium pentobarbital. Fifty microliters of treatment solution was instilled at end-expiration, and the liquid was followed immediately by $300 \mu \mathrm{l}$ of air to ensure delivery to the distal airways.

Immediately before sacrifice, animals were given intraperitoneal injections of sodium pentobarbital and the trachea was cannulated. The lungs were instilled with $4 \%$ paraformaldehyde in phosphate buffered saline at $20 \mathrm{~cm}$ of $\mathrm{H}_{2} \mathrm{O}$ constant pressure and carefully removed followed by immersion in the same fixative for $30 \mathrm{~min}$. The lungs were kept in $70 \%$ ethanol for storage. The left lungs were embedded in paraffin for histopathologic assessment.

\section{Histopathology assessment}

For histological examination, the paraffin sections were stained with haematoxylin and eosin (H\&E) and systematically analyzed with a microscope. The severity of pulmonary fibrosis among the groups was compared by using the Ashcroft score [7].

\section{Statistical analysis}

Group mean values and standard deviations of three independent tests were calculated using Microsoft Excel 2010. All data were subjected to Student's t-test, with $p<0.05$ considered significant.

\section{RESULTS}

\section{Maximum non-toxic dose (MNTD) of $\mathrm{H} 6552$ extract}

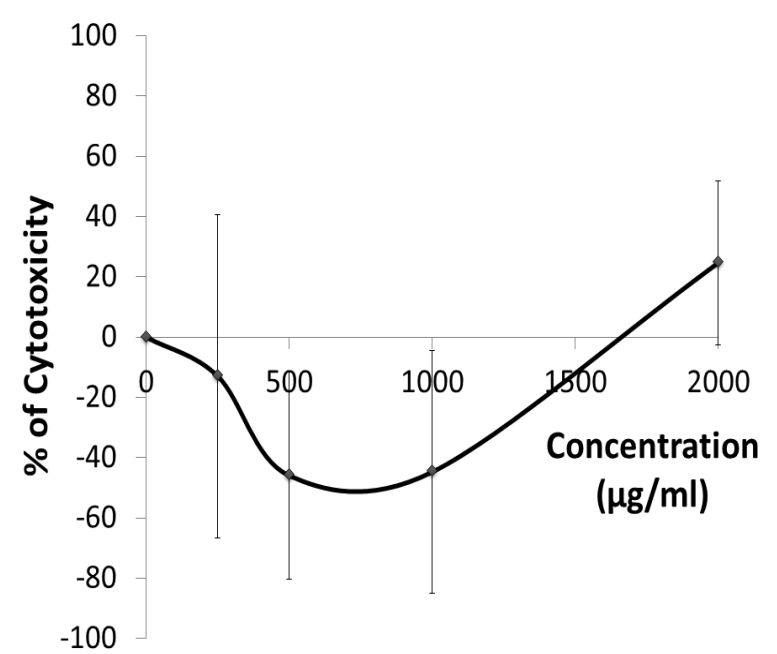

Figure 1: Cytotoxicity of $\mathrm{H} 6552$ extract on IMR-90 cells
The MNTD of the extract was determined to be $1625 \pm 459.62 \mu \mathrm{g} / \mathrm{ml}$ by using the MTT assay. H6552 extract at lower concentrations (250, 500 and $100 \mu \mathrm{g} / \mathrm{ml}$ ) did not show any cytotoxicity to the IMR-90 cells (Figure 1).

\section{Effect of H6552 extract on IMR-90 cell proliferation}

Population doubling time (PDT) of IMR-90 cells was calculated in order to determine the effect of H6552 extract on the cell proliferation. IMR-90 cells treated with TGF- $\beta$ showed decreased PDT, or a higher proliferation rate as compared to control. When the TGF- $\beta$-induced cells were treated with H6552 extract, PDT was found to be increased, particularly at the concentrations 250 and $1000 \mu \mathrm{g} / \mathrm{ml}$ (Figure 2). The greatest increase in PDT was achieved when the cells were treated with $\mathrm{H} 6552$ extract at $250 \mu \mathrm{g} / \mathrm{ml}$, in which an increase of $83.84 \pm 46.55 \%$ was observed. A slight increase in PDT was also observed in SB 431542-treated cells. However, the change was not statistically significant.

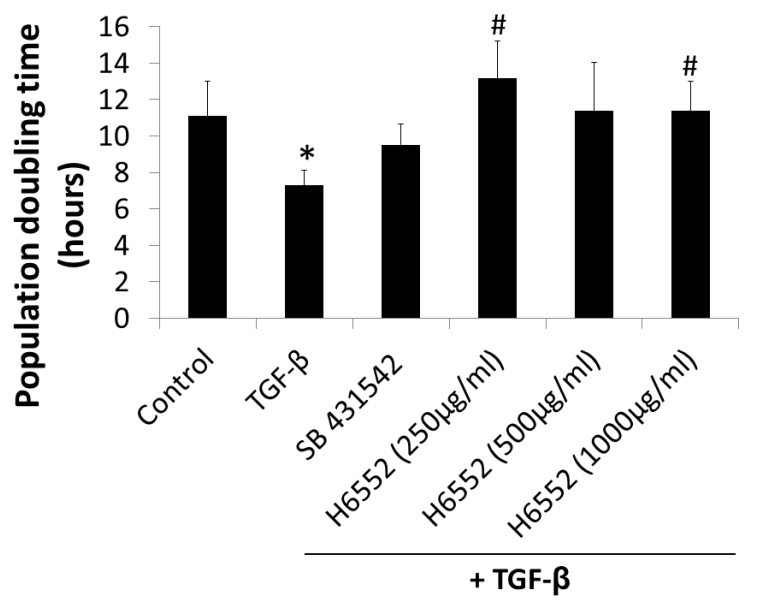

Figure 2: Effect of $\mathrm{H} 6552$ extract on IMR-90 cell proliferation. Cells were treated with various concentrations of $\mathrm{H} 6552$ extract for $24 \mathrm{~h}$. ${ }^{*} p<0.05$ compared with control group; \# $p<0.05$ compared with TGF- $\beta$ group

\section{Effect of $\mathrm{H} 6552$ extract on $\alpha$-smooth muscle actin ( $\alpha$-SMA) expression}

RNA of H6552-treated cells were harvested and Real-time PCR was performed to determine the a-SMA gene expression in IMR-90 cells. An almost 4-fold increase in the gene expression was noted when IMR-90 cells were exposed to TGF- $\beta$. However, the gene was drastically dropped to the basal expression level similar to the control when the cells were treated with SB 
431542 and $\mathrm{H} 6552$ extract $(500 \mu \mathrm{g} / \mathrm{ml})$ (Figure $3 A)$. H6552 extract at $1000 \mu \mathrm{g} / \mathrm{ml}$ also reduced the TGF- $\beta$-induced $\alpha$-SMA gene expression in IMR-90 cells $(p<0.05)$.

To further validate the $\alpha$-SMA inhibitory effect of H6552 extract, IMR-90 cells were immunostained with a-SMA antibody, followed by visualization under high magnification. Untreated control cells showed negligible staining, as indicated by a lack of brownish coloration in the cells. Control cells showed typical slender and elongated lung fibroblast morphology (Figure 3B). Upon stimulation with TGF- $\beta$, cellular morphology transformed to its activated myofibroblast form. The cells were enlarged and abundant a-SMA protein was expressed, as indicated by the strong brownish staining in the cytoplasm. Dense aggregates of microfilaments in the cells were also noted (Figure 3C). After treatment with $\mathrm{H} 6552$ extract $(500 \mu \mathrm{g} / \mathrm{ml})$, the cells regained its normal fibroblast features, whereby the spindle shape and weak immunoreactivity with the $\alpha$-SMA antibody were clearly seen (Figure 3D).

Total cell number and number of positively stained cells were also counted in the study. The determination of positively-stained cells showed that $\mathrm{H} 6552$ extract significantly reduced the number of cells that expressed a-SMA $(p<$ 0.001) (Figure 3E).
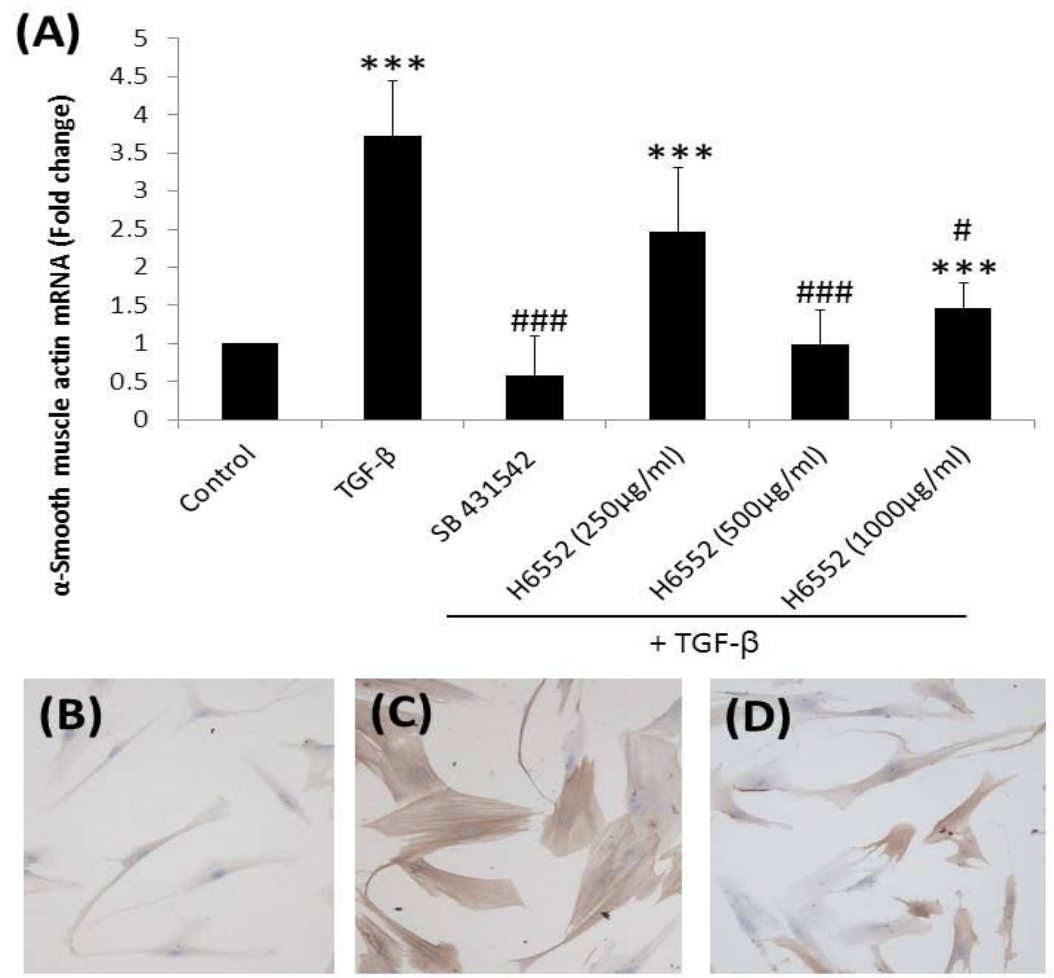

(E)

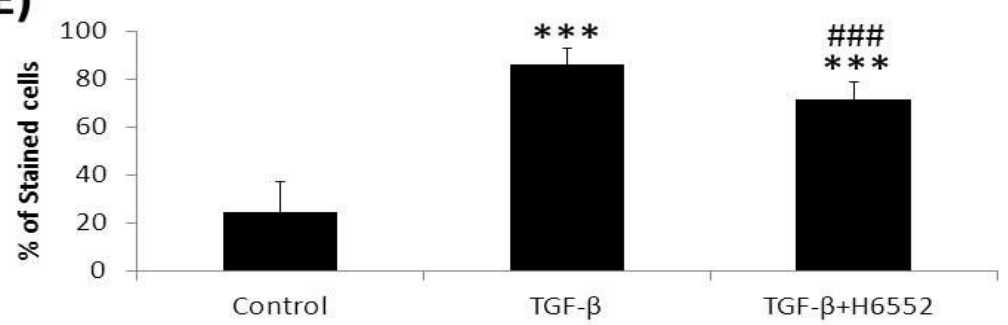

Figure 3: Effect of H6552 extract on a-smooth muscle actin ( $\alpha-S M A)$ expression. (A) a-SMA gene expression was determined by Real-time PCR. (B-E) a-SMA expression in IMR-90 cells was detected by immunostaining. Magnification: 200x. (B) Unstimulated IMR-90 cells served as control. (C) IMR-90 cells exposed to TGF- $\beta$. (D) TGF- $\beta$-induced IMR-90 cells treated with H6552 extract. (E) Percentage of positive staining cells for $\alpha$-SMA was assessed. All the results are expressed as mean $\pm \mathrm{SD}$ of three independent tests. ${ }^{* * *} p<0.001$ compared with control group; $\# p<0.05$ compared with TGF- $\beta$ group; \#\#p $<0.001$ compared with TGF- $\beta$ group 


\section{Effect of $\mathrm{H} 6552$ extract on collagen gel contraction}

IMR-90 cells were seeded in collagen gel matrix and the diameter of the gel was measured for the determination of percentage of contraction. It was noted that the collagen gel contracted gradually over the 4 days duration and significant decrease in the gel diameter $(p<0.001)$ was observed $96 \mathrm{~h}$ after the treatment with TGF- $\beta$. Gel contraction was inhibited with the addition of $1000 \mu \mathrm{g} / \mathrm{ml}$ of $\mathrm{H} 6552$ extract (Figure 4).

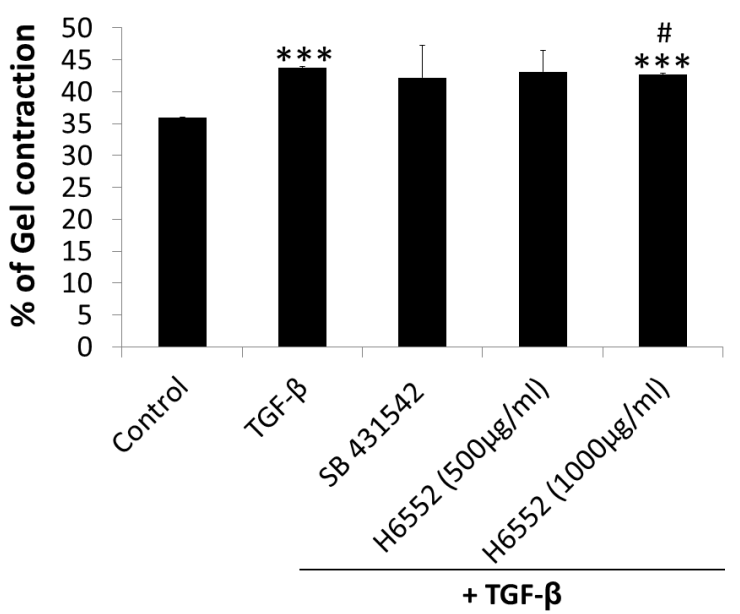

Figure 4: Effect of $\mathrm{H} 6552$ extract on collagen gel contraction. ${ }^{* * *} p<0.001$ compared with control group; $\# p<0.05$ compared with TGF- $\beta$ group

\section{Effect of H6552 extract on ICR mouse lung injury}

ICR mice were randomly divided into 10 treatment groups, each group consisting of 6 animals. Histologic assessment of lung samples was carried out using the Ashcroft scoring system and an average score was calculated to show the effect of $\mathrm{H} 6552$ extract on lung injury (Figure 5A). A higher score was given when fibrotic lesions were observed and inflammatory cell infiltration was present. The presence of the phenotypes suggested the presentation of lung injury.

It was obvious that when the animals received bleomycin instillation, their inter alveolar septum became thickened and the area was filled with leukocytes (Figure 5C) while the control animals had a single layer of epithelial cells lining up the alveolar sac and no inflammatory cells were present (Figure 5B). Bleomycin-induced mice which received treatments with $\mathrm{H} 6552$ extract showed $54 \%$ and $21 \%$ reduction in the injury score when treatment was given by early and delayed regimes respectively. Compared to the
H6552 extract, SB 431542 showed a milder effect in decreasing the lung injury score, in which $42 \%$ and $11 \%$ of reduction were noted for the early and delayed-treated groups respectively. Only the early treatment with $\mathrm{H} 6552$ extract decreased the average Ashcroft score significantly when compared to the bleomycin group $(p<0.05)$.

\section{DISCUSSION}

Abundant literatures show that fibrotic regions have increased expression of TGF- $\beta$, especially the isoform TGF- $\beta 1$, in the lung, kidney and liver [8]. Delivery of TGF- $\beta$ to the tissues causes severe fibrosis in experimental animals; and administration of TGF- $\beta$ binding proteins, such as neutralizing antibodies, soluble TGF- $\beta$ receptors and the proteoglycan decorin ameliorates fibrosis [9]. Results from these studies suggest that TGF- $\beta$ is a primary mediator in pathological fibrosis and it serves as a potential target to treat IPF. In this study, a TGF$\beta$ inhibitor extracted from the microbial strain $\mathrm{H} 6552$ [5] was used in both in vitro and in vivo assays to determine its anti-fibrotic effects.

The acetone extract of $\mathrm{H} 6552$ showed no toxicity on normal lung fibroblasts (IMR-90). Various concentrations of the extract ranging from 250$2000 \mu \mathrm{g} / \mathrm{ml}$ were tested on the cell line and the results showed that the extract induced moderate cell death only at the highest concentration (2000 $\mu \mathrm{g} / \mathrm{ml}$ ) (Figure 1). These suggested that compounds contained in $\mathrm{H} 6552$ extract are nontoxic towards lung cells and the extract may be safe to use in the treatment of pulmonary fibrosis.

The role of TGF- $\beta$ in the pathogenesis of pulmonary fibrosis has been well elucidated. It acts as a major inducer of fibrotic cell proliferation. Previous studies have proven that a significant increase in lung fibroblast proliferation up to $200 \%$ could be induced by TGF- $\beta$ [10]. A similar observation was noted in our study in which exposure of IMR-90 cells to TGF- $\beta$ enhanced their proliferation rates. The $\mathrm{H} 6552$ extract, which has been proven to be able to inhibit TGF- $\beta$ signal transduction [5], ameliorated TGF- $\beta$-induced cell proliferation. The extract delayed the population doubling time in a dosedependent manner (Figure 2). The antiproliferative effect of $\mathrm{H} 6552$ extract is relatively better than the positive control, SB 431542, a small-molecule inhibitor which binds to the TGF$\beta$ receptor.

Previous studies proposed that the augmentation in fibroblast proliferation might be due to 

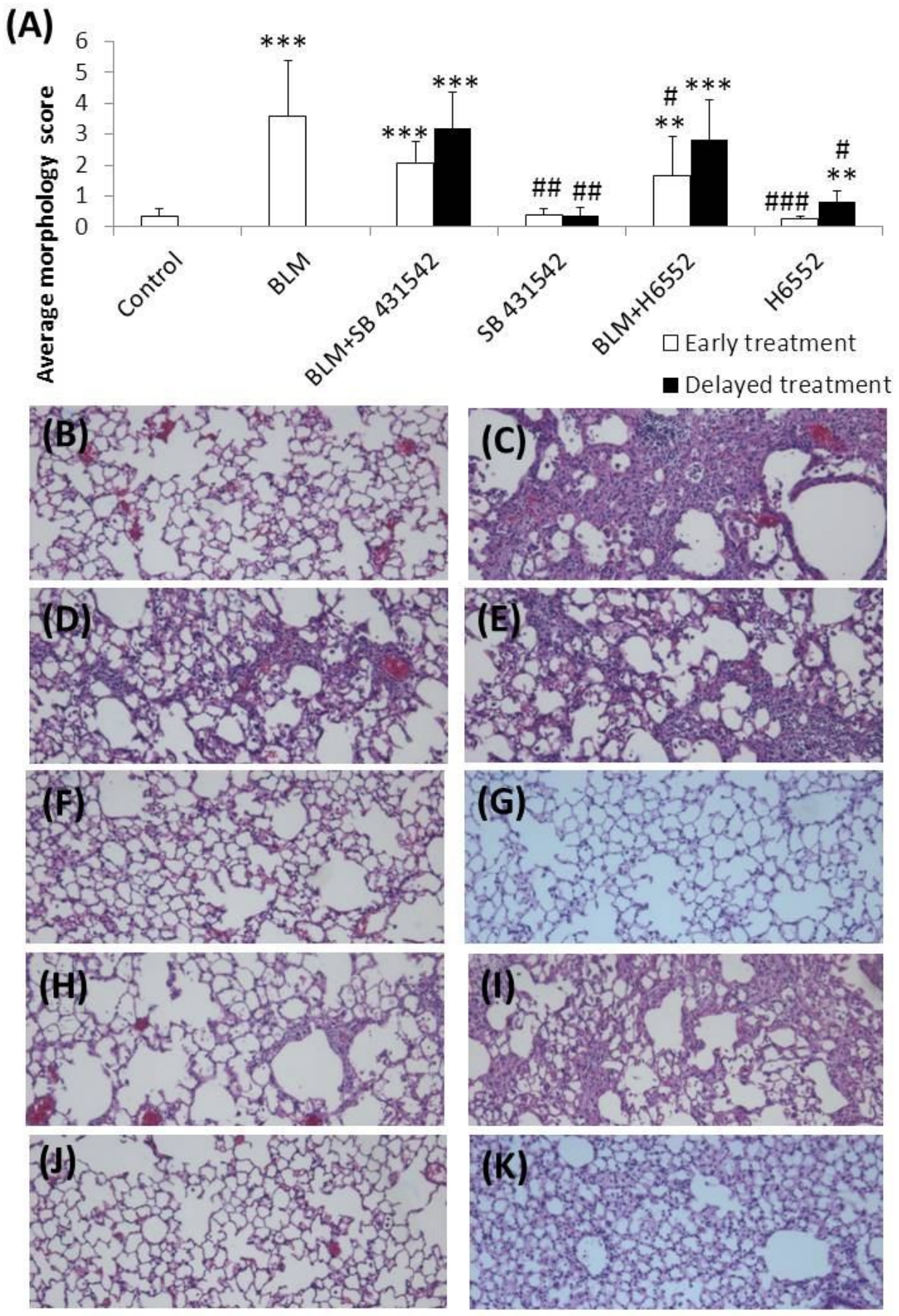

Figure 5: Effect of $\mathrm{H} 6552$ extract on lung injury in ICR mice. (A) The severity of the fibrotic changes in each lung section was assessed as a mean score of Ashcroft scale. (B-E) Representative H\&E staining of lungs of mice that received different treatments. Magnification: 100x (B) Control mouse. (C) BLM-instilled mouse. (D) BLMinstilled mouse receiving early treatment with SB 431542. (E) BLM-instilled mouse receiving delayed treatment with SB 431542. (F) Control mouse receiving early treatment with SB 431542. (G) Control mouse receiving delayed treatment with SB431542. (H) Bleomycin (BLM)-instilled mouse receiving early treatment with $\mathrm{H} 6552$ extract. (I) BLM-instilled mouse receiving delayed treatment with $\mathrm{H} 6552$ extract. (J) Control mouse receiving early treatment with $\mathrm{H} 6552$ extract. (K) Control mouse receiving delayed treatment with $\mathrm{H} 6552$ extract. The results are expressed as mean $\pm \mathrm{SD}(\mathrm{n}=6)$. ${ }^{* *} p<0.01$ compared with control group; ${ }^{* *} p<0.001$ compared with control group; \# $p<0.05$ compared with BLM group; \#\# $p<0.01$ compared with BLM group; \#\# $p<0.001$ compared with BLM group 
enhanced extracellular matrix synthesis such as fibronectin as well as cellular expression of smooth muscle actin [11]. Figure 3 shows that the H6552 extract had indeed reduced a-SMA expression in IMR-90 cells. The finding suggests that the changes in cell proliferation might be caused by the reduced $\alpha$-SMA production in cells.

Incorporation of $\alpha$-SMA in stress fibers was noted in wound contraction [12] and this led to the idea that $\alpha$-SMA might have a functional role in fibroblast contraction. Connective tissue contraction is another important aspect of fibrosis because the contraction and rearrangement of connective tissue may result in altered tissue structure and cause tissue dysfunction in fibrotic diseases [13].The present study showed that TGF- $\beta$ enhanced the contraction of collagen gel significantly, perhaps due to the increased level of a-SMA in the cells which in turn caused the generation of traction force which shrunk the gel matrix. On the other hand, addition of $\mathrm{H} 6552$ extract to the cells inhibited the contractile property of the fibroblasts (Figure 4). This suggests that the H6552 extract may show a therapeutic potential for the attenuation of excessive lung tissue contraction as observed in pulmonary fibrosis.

The effect of the $\mathrm{H} 6552$ extract was then further tested in an in vivo model of ICR mice. The pulmonary reaction that follows administration of intra-tracheal bleomycin in experimental animal had been extensively used as a model of human pulmonary fibrosis [14]. In addition, bleomycin was shown to increase type I collagen synthesis [15] and induce the synthesis and release of TGF- $\beta 1$ [16], which is suggested to contribute to tissue fibrosis in bleomycin-induced lung fibrosis [17]. Thus, the bleomycin-induced pulmonary fibrosis mouse model had been chosen in our study. The development of pulmonary fibrosis is thought to include two phases: a persistent inflammatory phase and a sequential fibrotic phase. Chaudhary et al [18] proposed that compounds administered during the early phase of fibrosis should be considered as 'preventive treatment' whereas 'true' antifibrotic agents might be effective irrespective of timing, particularly if administered during the 'fibrotic' phase of the model. Based on this concept, we administered H6552 extract in two regimes: the 'preventive' protocol (early treatment) and 'therapeutic' protocol (delayed treatment).

Results showed that the bleomycin-induced lung injury was abrogated only with the early treatment by $\mathrm{H} 6552$ extract. The delayed treatment did not reduce the injury score significantly (Figure 5). Shi et al [19] found that TGF- $\beta$ level peaked at 7 days after bleomycin instillation and the level decreased slowly after 14 and 28 days. This may reflect that TGF- $\beta$ may have a significant role during the early onset of fibrosis but may not contribute much at the later stage of the disease. Thus, the animal responded well to the TGF- $\beta$ inhibitor, H6552 extract at the early stage but not the later stage. Treatment with SB 431542 also reduced the lung injury score but the reduction was not statistically significant. In addition to lung injury measurement, the effect of the H6552 extract on collagen and $\alpha$-SMA was also being investigated. However, neither the early nor delayed treatments reduced collagen and $\alpha-S M A$ expression in the bleomycin-induced mice (data not shown). In short, we postulated that (1) the H6552 extract inhibited pulmonary fibrosis at an early phase of fibrogenesis but was not able to prevent the progression of the disease at the later stage; and (2) the extract was effective against the TGF- $\beta$-mediated inflammation but exerted no effect on other fibrotic markers such as collagen and $\alpha-S M A$ in the in vivo model.

While the in vitro data showed that $\mathrm{H} 6552$ extract down-regulated a-SMA expression, the in vivo model demonstrated otherwise. The contradictory observations may be due to the extract distribution and metabolism in animals upon administration. Intra-tracheal administration of the extract may have caused the compounds to be deposited at a confined expanse of tissue, which led to a comparatively small absorptive area. Upon absorption, the extract may have been metabolized by the lung tissue and this could have affected its net biological activity. In addition, little is known of the bioavailability of the extract. Taken together, these factors may cause the limited effects of the extract in inhibiting pulmonary fibrosis in vivo.

The current study is focused on the crude acetone extract from the H6552 actinomycete. However, further purification and isolation of bioactive compounds from the crude extract is crucial for the development of the compound as a potential TGF- $\beta$ inhibitor for pulmonary fibrosis. Chemical structure elucidation of the major bioactive compound within the extract is also imperative. Thus, further work is required to further explore the potential of $\mathrm{H} 6552$ metabolites as a novel anti-fibrotic agent.

\section{CONCLUSION}

Metabolites from the actinomycete strain H6552 inhibited TGF- $\beta$-induced pulmonary fibrosis, thus 
indicating it is a promising agent to treat the devastating disease.

\section{ACKNOWLEDGEMENT}

The authors would like to acknowledge the support of Ministry of Higher Education under project 04-01-07-104FR and Universiti Putra Malaysia under project 04/01/07/0113RU. Rhun Yian Koh was supported by the National Science Fellowship, Ministry of Science, Innovation and Technology. We thank Department of Physiology and Biomedical Sciences, Michigan State University, USA for co-sponsoring this study.

\section{REFERENCES}

1. Gribbin J, Hubbard RB, Le Jeune I, Smith CJ, West J, Tata LJ. Incidence and mortality of idiopathic pulmonary fibrosis and sarcoidosis in the UK. Thorax 2006; 61(11): 980-985.

2. Coultas $D B$, Zumwalt RE, Black WC, Sobonya RE. The epidemiology of interstitial lung diseases. Am J Respir Crit Care Med 1994; 150(4): 967-972.

3. Bonniaud P, Margetts PJ, Kolb M, Schroeder JA, Kapoun AM, Damm D, Murphy A, Chakravarty S, Dugar S, Higgins $L$, et al. Progressive transforming growth factor beta1-induced lung fibrosis is blocked by an orally active ALK5 kinase inhibitor. Am J Respir Crit Care Med 2005; 171(8): 889-898.

4. Li MO, Wan YY, Sanjabi S, Robertson AK, Flavell RA. Transforming growth factor-beta regulation of immune responses. Annu Rev Immunol 2006; 24: 99146.

5. Ho CC, Tan GYA, Seow I, Ajam N, Tan EL, Goodfellow $M$, Ward AC, Brown R, Wong NK, Lo CW, et al. Isolation, characterization and biological activities of actinomycetes isolated from dipterocarp rain forest soils in Malaysia. Singapore: Word Scientific; 2001.

6. National Research Council's Institute of Laboratory Animal Resources. Guide for the Care and Use of Laboratory Animals, 7th ed. Washington: National Academy Press; 1996.

7. Ashcroft T, Simpson JM, Timbrell V. Simple method of estimating severity of pulmonary fibrosis on a numerical scale. J Clin Pathol 1988; 41(4): 467-470.

8. Branton MH, Kopp JB. TGF-beta and fibrosis. Microbes Infect 1999; 1(15): 1349-1365.
9. George J, Roulot D, Koteliansky VE, Bissell DM. In vivo inhibition of rat stellate cell activation by soluble transforming growth factor beta type II receptor: a potential new therapy for hepatic fibrosis. Proc Natl Acad Sci USA 1999; 96(22): 12719-12724.

10. Kunzmann S, Schmidt-Weber C, Zingg JM, Azzi A, Kramer BW, Blaser K, Akdis CA, Speer CP. Connective tissue growth factor expression is regulated by histamine in lung fibroblasts: potential role of histamine in airway remodeling. J Allergy Clin Immunol 2007; 119(6): 1398-1407.

11. Tufvesson E, Westergren-Thorsson G. Biglycan and decorin induce morphological and cytoskeletal changes involving signalling by the small GTPases RhoA and Rac1 resulting in lung fibroblast migration. J Cell Sci 2003; 116(Pt 23): 4857-4864.

12. Darby I, Skalli O, Gabbiani G. Alpha-smooth muscle actin is transiently expressed by myofibroblasts during experimental wound healing. Lab Invest 1990; 63(1): 21-29.

13. Evans JN, Kelley J, Low RB, Adler KB. Increased contractility of isolated lung parenchyma in an animal model of pulmonary fibrosis induced by bleomycin. Am Rev Respir Dis 1982; 125(1): 89-94.

14. Borzone G, Moreno R, Urrea R, Meneses M, Oyarzun M, Lisboa C. Bleomycin-induced chronic lung damage does not resemble human idiopathic pulmonary fibrosis. Am J Respir Crit Care Med 2001; 163(7): 1648-1653.

15. Roberts $A B$. Transforming growth factor-beta: activity and efficacy in animal models of wound healing. Wound Repair Regen 1995; 3(4): 408-418.

16. Hoyt DG, Lazo JS. Alterations in pulmonary mRNA encoding procollagens, fibronectin and transforming growth factor-beta precede bleomycin-induced pulmonary fibrosis in mice. J Pharmacol Exp Ther 1988; 246(2): 765-771.

17. Clark JG, Starcher BC, Uitto J. Bleomycin-induced synthesis of type I procollagen by human lung and skin fibroblasts in culture. Biochim Biophys Acta 1980; 631(2): 359-370.

18. Chaudhary NI, Schnapp A, Park JE. Pharmacologic differentiation of inflammation and fibrosis in the rat bleomycin model. Am J Respir Crit Care Med 2006; 173(7): 769-776.

19. Shi K, Jiang J, Ma T, Xie J, Duan L, Chen R, Song $P$, Yu Z, Liu C, Zhu Q, et al. Pathogenesis pathways of idiopathic pulmonary fibrosis in bleomycin-induced lung injury model in mice. Respir Physiol Neurobiol 2014; 190: 113-117. 